\title{
Genetic transient congenital hypothyroidism
}

INSERM

\section{Source}

INSERM. (1999). Orphanet: an online rare disease and orphan drug data base. Genetic transient congenital hypothyroidism. ORPHA:226316

Genetic transient congenital hypothyroidism is a rare, thyroid disease characterized by a gene mutation induced, temporary deficiency of thyroid hormones at birth, which later reverts to normal with or without replacement therapy in the first few months or years of life. 